\title{
Impact of Self-help Group in Socio-economic development of India
}

\author{
Dr.A.Sundaram, \\ Associate Professor, Dept. of Economics, Govt Saiha College, Affiliated to Mizoram University, Saiha, \\ Mizoram, North East India-796901
}

\begin{abstract}
The SHG method is used by the government, NGOs and others worldwide. Thousands of the poor and the marginalized population in India are building their lives, their families and their society through Self help groups. The main aim of this paper is to examine the impact of Self-help Group in Socio-economic development of India. Self-help Groups have been playing considerable role in training of Swarozgaris, infrastructure development, marketing and technology support, communication level of members, self confidence among members, change in family violence, frequency of interaction with outsiders, change in the saving pattern of SHG members, change in the cumulative saving pattern of SHGmembers per month, involvement in politics, achieving social harmony, achieving social justice, involvement in community action, sustainable quality and accountability, equity within SHGs,defaults and recoveries, and sustainability financial value. It analyses what is Self-Help Group? Why the Self-Help Group is so important in India? The present status of Self-Help Group in India, impact of Self-Help Group in India, Shortcomings of Self-Help Group in India, Suggestions to improve Self-Help Group In India, conclusion.
\end{abstract}

Keywords: Poor, Self-Help Group, achieving Social Justice, Sustainable quality, Equity, Empowerment

\section{Introduction}

Self-help group is a method of organising the poor people and the marginalized to come together to solve their individual problem. The SHG method is used by the government, NGOs and others worldwide. The poor collect their savings and save it in banks. In return they receive easy access to loans with a small rate of interest to start their micro unit enterprise. Thousands of the poor and the marginalized population in India are building their lives, their families and their society through Self help groups. The 9th five year plan of the government of India had given due recognition on the importance and the relevance of the Self-help group method to implement developmental schemes at the grassroots level.

Self Help Group (SHGs)-Bank Linkage Programme is emerging as a cost effective mechanism for providing financial services to the "Unreached Poor" which has been successful not only in meeting financial needs of the rural poor women but also strengthen collective self help capacities of the poor ,leading to their empowerment.

The main aim of this paper is to examine the impact of Self-help Group in Socio-economic development of India. It analyses what is Self-Help Group? Why the Self-Help Group is so important in India? The present status of Self-Help Group in India, impact of Self-Help Group in India, Shortcomings of Self-Help Group in India, Suggestions to improve Self-Help Group In India, conclusion.

\section{Why Self-Help Group Is So Important In India?}

1.1. To alleviate poverty

1.2. To increase employment opportunity

1.3. To accelerate economic growth

1.4. To raise status in society is the prime reason for respondents joining the SHG

1.5. To promote income generating activities

1.6.

\section{What Is The Present Status Of Self-Help Group In India?}

Even after more than 62 years of planning, various poverty alleviation programmes, official estimates shows that around 26.1 percent of total population still lives below the poverty line in India the financial requirement is one of the basic needs of the poor rural people of the society for their socio-economic upliftment. Amongst the poor the most disadvantageous group are the women and they constitutes almost half of the population of India.

According to new data, 29.8 per cent or 360 million Indians were poor in 2009-10 as compared to 37.2 per cent or 400 million in 2004-05. However, the decline is based on a poverty line calculated at Rs.22.43 per 
person per day in rural areas, and Rs.28.65 per person per day in urban areas, which is lower than the earlier Rs.32 a day mark.

In rural areas, Scheduled Tribes exhibit the highest level of poverty (47.4\%), followed by Scheduled Castes (SCs), (42.3\%), and Other Backward Castes (OBC), 31.9\%), against $33.8 \%$ for all classes. In urban areas, SCs have HCR of $34.1 \%$ followed by STs (30.4\%) and OBC (24.3\%) against $20.9 \%$ for all classes.

Nearly $50 \%$ of agricultural labourers and $40 \%$ of other labourers are the poverty line in rural areas, whereas in urban areas, the poverty ratio for casual labourers is $47.1 \%$. Monthly per capita incomes of Rs 859.60 in urban regions and Rs 672.80 in rustic regions, respectively, have been determined as the novel poverty line.

The unemployment rate in India was last reported at 9.4 percent in 2009/10 fiscal year. Historically, from 1983 until 2010, India Unemployment Rate averaged 8.11Percent reaching an all time high of 9.4 Percent in December of 2009 and a record low of 5.9 Percent in December of 1994. The unemployment rate can be defined as the number of people actively looking for a job as a percentage of the labour force.

While India's unemployment rate has dropped from $8.2 \%$ in $2004-05$ to $6.6 \%$ in $2009-10$, the number of jobless is still huge in absolute terms. The country added some 11.7 million people to the workforce between 2004-05 and 2009-10, and the labour pool, based on the 2009-10 national sample survey, and is estimated at 428.9 million. Over half the country's workforce is self-employed and women receive less pay than men for similar jobs, latest government data shows. While $51 \%$ of the country's total workforce is self-employed, only $15.5 \%$ are regular wagers or salaried employees and $33.5 \%$ casual labourers, according to a survey by the National Sample Survey Office (NSSO).

The proportion of the self employed (vulnerable workers) has declined significantly in the development process. The proportion of self employment in the total employment is as low as $8 \%$ and $10 \%$ for women and men respectively in developed regions and as high as $64 \%$ and $57 \%$ for women and men in developing regions.

In India the overwhelming proportion of workers is in the self employment category. About $64 \%$ of the rural and $46 \%$ of the urban workforce is engaged in self-employment. In India $20.51 \%$ of the workforce are living below the poverty level. The proportion is highest $(31.9 \%)$ among casual labour and second highest $(17.17 \%)$ among the self employed. However, in terms of absolute number, the self employment category has the highest number of poor -45.28 million, followed by casual labour -41.45 million.

As per 2001 census 48.2 percent (49.60 crores) of total population are women, while the 2011 census provisional figures released on 31 March 2011 reveals that the female population has risen by 18.12 percent to reach 586.5 million (58 crores). Microfinance to Self Help Groups (SHGs) may be considered as a vital tool for meeting the Women constitute around fifty percent of the total human resources in our economy.

According to the Chaitanya and Chalana study, it is an excellent program. If the scheme is implemented properly, there will be no need for another scheme (Chaitanya and Chalana (undated).

The only way to lower the risk that the rural poor face would be to reduce their vulnerability through the use of microfinance to engage positively in capacity building.

\section{Impact Of Self-Help Group In India}

\subsection{Saving and Financial Decision Making}

One of the primary benefits of participation in a SHG is the opportunity to save regularly, access formal savings institutions and participate in the management of these savings. They save regularly, have their own bank accounts and make deposits into these accounts. SHG is having a good impact on members, in their ability to save their hard earned money.

\subsection{Access to credit}

A corollary of participation in SHGs is an improvement in a woman's access to credit. Since the project is perhaps too early in its implementation to directly improve women's access to credit. The financial mobility due to participation in the SHG has led to an improvement in the quality of life, according to some of the successful groups. Overall, many families were able to address their basic needs better than before. Some of NGOs reports have shown that the record on the repayment of loans by women was often better than that of men, and that women were also more likely to spend the income earned, on their families, leading to improved health and nutrition of the poor population and for improving the quality of their lives.

\subsection{Employment:}

The implementation of SHG has generated Self-employment opportunities for the rural poor. The progress of the program since inception assisted in formation of 35.7 lakh SHGs; assisted 1.24 Cr. Swarozgaris in establishing their own micro-enterprises. The Government of India released Rs.11, 486 Crore under the program; bank credit mobilization is Rs.19, 017; Total subsidy provided is Rs.9, 318 Cr. The program helped many participants in improving their economic conditions. Another good accomplishment of the program is that 
it has adopted the SHG strategy. The number of assisted SHG/ group Swarozgaris has increased from 35,000 in 1999 - 00 to 1.15 million in $2007-08$. At the same time the number of assisted individual Swarozgar has declined from 586 thousand in 1999 - 00 to 254 thousand in 2007 - 08. The National Bank for Agriculture \& Rural Development (Nabard) will create a Rs.15 billion fund to cater to women's Self-Help Groups in economically weaker districts in the country,

After joining the self help group the women are economically and socially empowered. This empowerment cannot be transformed or delivered it must be self generated such that it enables those who are empowered to take control over their lives.

\subsection{Decision-making within the household}

The social impact of the SHG program increased involvement in Decision-making, awareness about various programs and organisations, increased access to such organisations, increased expenditure on Health and Marriage events, there is a Change in the attitude of male members of the families, now they are convinced about the concept of SHG and encourage women to participate in the meetings and women reported that they have savings in their name and it gives them confidence and increased selfrespect. Within family the respect and status of women has increased. Children Education has improved significantly. Especially girl education was very low but now SHG members are sending their children including girls to school. The Sanitation in members' households has improved and it has led to better health in members' families. Now women are taking treatment from qualified doctors, even if they have to travel to nearby towns. Members are now confident enough to raise social status.

\subsection{Participation in local government}

Because of SHG, women know about their local political institutions such as the Gram Panchayats and have better knowledge of where to report certain types of grievances. As part of the political empowerment process, it is a pertinent fact that many women have not only been elected to the Grama Panchayats but have become the role holders too.

In a majority of the cases, the women perceived themselves as now having some influence over decisions in the political life of village, and in a smaller number of cases, the women named their participation and influence in village political life as an important and note-worthy change. However, in general, the opportunities available to the women to participate in village life were limited, as most of the village processes were still being male-dominated and patriarchal. Though the SHGs generate positive impact on the rural economy through empowering women and enhancing the rural income of those participant households, the issue of group size has been of long standing concern.

\subsection{Communication Level of Members}

Microfinance movement is having a good impact on members, in their ability to express their feelings and has made people more confident to express themselves.

\subsection{Self Confidence among Members}

The group formation brought out the hidden talent and leadership qualities among the members. Therefore, it can be concluded that after joining the SHG the members have improved their status in family, become helpful in family finance and sometimes helped others too.

Now, most of the SHG people feel that they get more respect; not only in the village, but our own family members treated us more respectfully. People of the village now invite us for social and community functions. Now our family members value our opinions whereas earlier they had no use for it. They encourage us and support us in our activities". "Now they get respected in the village society and have a definite identity in society. Family members think of them as a working woman and encourage them in their work". Improve their knowledge of banking, of how to undertake the different banking transactions, as also of dealing with government officials. They now feel confident about these things. They too feel an improvement in their social status. Family members changed their attitudes towards them after they started participating in the SHG. They now regard them brave women. The people of the village too give much more respect than before". Family members seek her opinion in many of the family decisions. Moreover, people from the society in general respect them.

\subsection{Change in Family Violence}

Involvement with SHG has reduced this violence in 25 per cent cases especially due to reduction in economic difficulties. In most of cases the members revealed that their husbands should also be involved in SHGs. 


\subsection{Frequency of Interaction with Outsiders}

Members generally, got lesser opportunity to interact with bankers, Government officials, NGOs and others in the Pre-SHG period. It can be seen that in the Pre SHG period 25 per cent of the members were not interacting with officials whereas after associating with SHGs, 91 per cent members had interacted with the outsiders and out of total 44 per cent have interacted more than 4 times with outsiders. This interaction helped them to articulate their problems and improved their self-confidence.

\subsection{Status of Access to Amenities}

Since SHG programme has economic as well social implications. It can be seen that there has been an increase of 40 per cent in SHG members in terms of their status of access to amenities factors. Therefore, it can be concluded that after joining the SHG the members have improved in getting access to amenities like medical, sanitation, education, market, water supply, transport.

\subsection{Community Participation}

SHG members undertook a lot of community activities which they earlier could not have imagined themself to have done. They distributed school uniforms to poor students; they undertook a plantation drive, distributed pen and notebook sets to poor students and donated some money to a charity during a national calamity. They participated in several social initiatives like the "Clean Village Drive" and other such social upliftment programmes since their involvement in the SHG. They organized a small function on India's Republic day. Perspective of the Social Worker Women who have participated in this have benefited economically. They are now able to buy household goods like televisions, furniture, telephones, jewellery and most importantly are able to save for the future. "Now they are much more confident in their dealings with government officials, bank officials, electricity board officials, Medical officers, the revenue officer, health scheme officials etc. They also participate in elections. Moreover, they make use of the various government welfare schemes available".

How over the years, women who have barely completed their schooling, who could earlier barely step out of their houses to talk to government officials or other village men, are today stepping out and caring for themselves and their communities with confidence. An interesting development is that the men, unlike earlier, are now encouraging women to step out of their houses to work and participate in these social and community events. Whether this is a welcome change or not needs to be understood. It has to be also understood why they are doing so.

One reason they could be doing so is because of the increased household incomes and ready access to credit that the SHG participation of the women is resulting into. Sometimes this situation can be exploited if the men are alcoholic, so that the credit is actually wasted away. In this regard, however, the women are alert and aware and the SHG participation has given them the collective strength to stand up to it. They collectively stop any man from abusing his wife under the influence of alcohol.

Now they are able to meet each other and discuss their problems. They understand each other's viewpoints and problems. Interaction with other women has resulted in building congenial relationships and has ensured fewer conflicts. It has also had the multiplier effect of spreading the SHG movement. Awareness of health related issues, personal hygiene, communicable diseases; effects of malnutrition, environmental issues, and sanitation have also increased as a result of training programs and their participation in the related projects.

\subsection{Increased Nutritional status}

They find positive impacts on empowerment and nutritional intake. Female social and economic empowerment in program areas increased irrespective of participation status. Evidence of higher consumption is not income or asset formation. the program's main economic impact had been through consumption smoothing and diversification of income sources rather than exploitation of new income sources.

\subsection{SHGs and Environmental Management}

Research and policy has tended to focus on the relationship between poverty and environmental degradation in terms of pointing out that the poor are both victims and agents of environmental degradation. They are victims in that they are more likely to live in ecologically vulnerable areas, agents in that they may have no option but deplete environmental resources thus contributing to environmental degradation.

As a result of increasing awareness, social conditions and poverty alleviation, are necessary to support environmental sustainability (SIDA 1996; Leach and Mearns 1991; UNEP 1995).Today SHGs have a role to play in poverty alleviation through empowerment of women in India. Moreover, women tend a greater involvement in environmentally sustainable activities and environmental management than men. Therefore, involvement of women in development programmes through SHGs can effectively increase awareness of society to ward environmental sustainability. 


\section{Shortcomings' Of The Self-Help Group In India}

Though it was considered as a wonderful program by many stakeholders, the program failed on many counts is provided as follows:

\subsection{Challenge of take off}

The program supported promotion of 292 thousand SHGs in the first year, i.e. 1999 - 00.The number remains around this level in all subsequent years with wide fluctuations from year to year. Similarly, 214 thousand groups passed Grade - I, in the second year of the program, i.e. 2000 - 01. It remains around this level in all subsequent years.

Though there is significant growth in the number of groups that passed Grade - II, groups which have taken up economic activities are less. In total only 685 thousand groups have taken up economic activities. It is a little over one-fifth of groups promoted in the scheme.

\subsection{Funds allocation and utilization}

The allocation of funds for the SGSY scheme by both central and states' governments was Rs.1, 472 cr. in $1999-00$, the first year of the program. In the subsequent 7 years, the allocation remained below that of the first year. It was nearly half of the first year allocation in $2001-02$ and $2002-03$.

The total amount allocated for the program during 10 years is Rs.14, $467 \mathrm{cr}$. It is less than half of the budgetary allocation of Rs.30, 100 cr. for NREG in just one year, i.e. 2009 - 10. The principal reason for stagnation in funds allocation is non-cooperation of banks. The allocated meagre amounts were not fully utilized even in one year during the last 10 years program period. Total utilization is $74 \%$ of funds made available. However, the utilization ratios are increasing over the years. It has increased from $49 \%$ in $1999-00$ to $86 \%$ in 2003 - 04. It remains well over $80 \%$ in the subsequent years.

Though there is provision for utilizing of $10 \%$ of allocated funds for training and another $20 \%$ for development of critical infrastructure, utilization of funds in these two activities is quite less and relatively more funds were used for providing subsidies and grants to SHGs and individual Swarozgaris. As a result the program is often known as subsidy oriented program.

\subsection{Credit mobilization}

Mobilizing bank credit is a major challenge of the program, due to which the governments at centre and states could not increase the allocations over the years. In total, the target of credit mobilization is Rs.29, $831 \mathrm{cr}$. But little over half of that amount was mobilized during the last 10 year. However, the proportion of actual mobilization to target is increasing over the years. It is a healthy sign. Because of lower than targeted mobilization of bank credit and allocation of a relatively higher proportion of funds for subsidy, the ratio of credit to subsidy was about two during the period and did not vary much from year to year. Thus, the creditsubsidy ratio remained much below the target ratio of 3:1 (GoI, 2009). It also resulted in less than planned investment per Swarozgar.

\subsection{Challenge to target the real poor and vulnerable sections}

A comprehensive study by BIRD, 2007 on coverage of SCs/ STs in SGSY, which covered 10,848 Swarozgaris and non-Swarozgaris (control sample), pointed out exclusion of SCs and STs in the following ways and for the following reasons.

Physical exclusion - by not being accepted as group members, Financial exclusion by denial of their due share either by group leaders or by implementing bank or block officials, Exclusion because they are already covered under some state government sponsored programs (often implemented by state (ST/ SC corporations) and in many cases are already defaulters of bank loans (BIRD, 2007). About $60 \%$ of the non-Swarozgaris (control sample) were found to be sure about their inclusion in the BPL list (BIRD, 2007). A more dismal picture is provided by a MoRD (2007) briefing, which shows that SGSY covers only $1 \%$ of the relevant household population, and only $33 \%$ of its beneficiaries are drawn from the poorest quintile, whereas as many as $14 \%$ are from the richest and $26 \%$ are from the two richest quintiles.

Further, the total benefits are even more inequitably distributed with the richest quintile receiving as much as $50 \%$ as compared to $8 \%$ for the poorest (as quoted in Tankha, et al. 2008). The annual report of MoRD $2002-03$, reported that in most of the areas, especially in Bihar and Uttar Pradesh, influential persons in villages were found to own a group (as quoted in GoI, 2009).

\subsection{Low survival rate of promoted micro-enterprises}

Many assisted Swarozgaris are either reluctant to create or acquire the planned assets or were disposing them immediately after acquiring. According to BIRD's study “in northern states, the success rate in terms of whether units exists or not in case of units financed to group Swarozgaris turned out to be even worse than that 
in case of individual Swarozgaris as only $17.7 \%$ units were found to be existing in case of group Swarozgaris as against the $31.11 \%$ units intact in case of individual Swarozgaris. The results indicate just opposite pattern to what most of us believe/ perceive that group approach of financing is better than the individual financing. However, in case of southern states, $76.6 \%$ units were found to be existing at the time of field visits which shows the better care by the government department as far as monitoring of units is concerned" (BIRD, 2007).

The present author observed that in Andhra Pradesh some groups manipulated acquiring of assets/ livestock. According to the group members, they sent their buffaloes to their relatives'/ friends' houses a day before the proposed transaction. The next day they acted as if purchasing (their own) livestock from their relative/ friend in front of the officials. The Government of AP noticed these kinds of problems long ago and converted capital subsidy into interest subsidy in 2004. Now one hardly hears words like SGSY, subsidy and revolving fund among SHGs in rural areas of Andhra Pradesh. One can only hear the words 'Pavala Vaddi' or ' $3 \%$ interest loans'. In other states, many studies reported that groups' focus is on subsidy. They dispose the capital/ livestock immediately, repay the bank loan and distribute the subsidy amount (see e.g. APMAS, 2008; Tankha, et al, 2008; BIRD, 2007).

\subsection{Low realized incremental income from Income generating activities}

The program envisaged that Swarozgaris would realize about Rs.2, 000 per month from the investment of about Rs.25, 000. Except a few case studies, no major evaluation study reported additional income anywhere close to Rs.2, 000 per month. In $2002-03$, only $43 \%$ of the assisted Swarozgaris reported an increase in their income (as quoted in GoI, 2009). A rigorous study by Pathak and Pant (2006) in Jaunpur district of UP shows that SGSY has not contributed significantly to the change in the level of income of the beneficiaries (as quoted in Tankha, et al, 2008).

According to a NIRD (2008) study, even in the better performing State of Andhra Pradesh the income gain to a Swarozgar from enterprise activities under SGSY was a mere Rs.1,228 per month (as quoted in GoI, 2009). BIRD presented an even grimmer picture. According to their study the poor income generation in both the cases of individual Swarozgaris (Rs.9, 391) and The group members shared these old stories (6 to 7 years old), since then they have repaid their loans and all officials got transferred.swarojgaries (Rs.6, 916 in northern states and Rs.11, 089 in southern states) per member per annum suggests for serious thinking about implementation of the program in its present format. Certain success stories, here and there should not be read as final outcome of the program and at the best, these can be documented and evaluated so that the reasons for success can be internalized into the future policy guidelines. The program also breaks the great myth that 'group approach of lending' is always better than the individual approach of financing (BIRD, 2007). Needless to say, that the above figures are only of surviving units. If failed units were also included, the average incremental income would be around a few hundred rupees or less. It may be recalled that about $50 \%$ of the Swarozgaris have taken up dairy. About another quarter has taken up other livestock rearing, including poultry and other primary activities. It is surprising to note that Indian villagers need training in activities like livestock rearing, the primitive and primary occupation in the country

\subsection{Suggestions for designing the NRLM}

\section{Suggestions To Improve Self-Help Group In India}

As three-fourths of households in the country are either poor or vulnerable, NRLM may cover all willing rural households, irrespective their BPL or APL status, in the SHG program for effective financial inclusion.

It may be divided into two sub-programs, viz. Financial Inclusion and Livelihood promotion.

Two programs may be implemented sequentially. The first five years may be totally focusing on promotion and strengthening of SHG institutions and later focus may be on setting up of small and medium enterprises under SHG federations.

\subsection{Suggestions to promote Financial Inclusion}

1.27.1. SHG banking may be allowed to function as core banking activity without any outside interference like target fixing, interest cap, loan size, etc.

1.27.2. The Government may promote quality SHGs through village/ cluster level; sub-district/ block level and district level federations.

1.27.3. Wherever banks are not accessible or not responsive, federations may be prepared to take up financial intermediation

1.27.4. Promoting agencies play a crucial role in developing quality institutions. Promoting agencies may be given adequate financial and capacity building resources and timeframe. Available evidence indicate that investment of about Rs.15,000 per SHG for 8 to 10 years is required to promote quality SHGs with strong federations and effective livelihood opportunities. 
1.27.5. Promoting agencies should have a clear role transformation strategy and should implement the same in letter and spirit

1.27.6. NRLM may work on sensitization and orientation to bankers about the commercial value of SHG banking.

1.27.7. NRLM may understand the banks' concerns such as quality of groups, political interference in functioning of federations, wrong signals like loan waivers, etc and address them.

1.27.8. NRLM may provide interest subsidy as given in AP.

\subsection{Suggestions for promotion of small and medium enterprises}

To obtain desirable employment transformation and to take full advantage of booming secondary and tertiary sectors, NRLM may focus on manufacturing and service sectors. The small and medium enterprises may be promoted to village/ cluster; sub-district/ block and district level SHG federations.

1.28.1. The potential units could be agro-processing units; milk processing units; common service providing units; cold storages; rural warehouses; market yards to organize weekly markets; etc

1.28.2. Appropriate institutions like 'commodity cooperatives' and 'producer companies' may be promoted under SHG federations to take up small and medium enterprises as per the pattern of the borrowing from the SHGs.

1.28.3. The federations could be assisted to have state of the art units by hiring professional consultancy firms, who can provide these units on turnkey basis.

1.28.4. NRLM may provide investment and working capital to the federations to set up these units

1.28.5. If banks are non-responsive, the apex financial institutions like state finance corporations/ SIDBI/ NABARD could be accessed.

1.28.6. Acquired units could be pledged as security to the banks and financial institutions.

1.28.7. These units would result in development of entrepreneurship in federations, provide a large number of regular employment opportunities to the members and boost the rural economies.

1.28.8. SHG concept should target the holistic development of women members. The ministry may bring out publications pertaining to different aspects of SHG and its development / empowerment.

1.28.9. It is felt that efficiency and effectiveness of SHG should be regularly monitored by a qualified and designated body to give corrective input wherever necessary as well as encourage the deserving ones.

1.28.10. Timely release of adequate loans and the eligible subsidy is important.SHG member education and awareness on the high poverty regions should be viewed as long term investment in human capital development.All stakeholders should invest their time for capacity building, handholding and development support.

\subsection{Suggestion for better Implementation of machinery}

Implementation mechanism may follow the design of the program. It may be kept in mind that a proper role transformation strategy and implementation of the same in letter and spirit is essential for the development of people's institutions. After joining SHG the income levels of the respondents have increased and with the help of increased income level they could overcome the poverty. Loan facility is available for all the members without any restriction. Thus SHGs are formed with the idea of mobilizing small savings from the members. SHGs are not treated as financial system but they are formed with a view to social and economic change of the rural people especially for the rural women.

E.Improper emphasis should be given to group lending and SHGs formulation for alleviate poverty. In avoiding of any misuse of money, there should be a need of proper regulating authority at each level such as saving, depositing, and money lending. Periodical training programme at regular intervals to group members may be organised by the NGOs and other Government officials to aware about bank loan, proper accounts keeping, self management, decision making etc. Attendance at meeting and workshops should be made mandatory so that the members can enhance their group cohesiveness.

Women should be properly educated so that they will enhance the capability to manage communities and community projects. The NGOs and the State government must also monitor at a regular interval the overall performance of SHGs and the members included in it. There is a need for establishing a computerized MIS for SHGs and SHG federations to monitor their performance on a regular basis.

\section{Conclusion}

SHG Programme clearly plays a central role in the lives of the poor. The programme in various blocks all seem to be very successful in reaching poor clients Importantly; there is evidence of increased household income. This is a very significant indicator of impact. Standard of living for the program participants have 
increased and also the food security is much more for the program clients. Programme loans are one of the main ways clients overcome food insecurity with sickness, disease, emergencies and crises, where programme participants seem to transfer the loan source from friends and moneylenders to SHG loans to meet these expenses.

At the individual level, there is evidence that the programme attracts already relatively empowered people and that empowerment occurs among some clients through programme participation. The process of empowerment manifests itself in increased self-esteem. Programme participation is also associated with changes in decision-making at the family level. Program participants are far more aware about the various programs and organisations and have an access to these organisations.

Microfinance is playing a significant role in alleviate poverty and rural development. Since women are the sole family caretaker, proper emphasis should be given to the rural women and for empowering the rural women finance is required. Microfinance to the rural SHGs is a way to raise the income level and improve the living standards of the rural women. The Self Help Groups have proved the way for economic independence of rural women. Thus, it can be concluded that the self help groups contribute substantially in pushing the conditions of the female population up and through that chip in poverty eradication as well. From the above analysis we can conclude that inspite of the concerted efforts taken by SGSY, it is clear that the failure of the programme is seen. But of course there are lot of advantages as well as disadvantages. Now MoRD has been taking a lot of initiatives to revamp the programme. Let us hope that better solutions coming up to implement the programme in effective and efficient ways and means in the near future.

Self-help Groups have been playing considerable role in training of Swarozgaris, infrastructure development, marketing and technology support, communication level of members, self confidence among sample members, change in family violence, frequency of interaction with outsiders, change in the saving pattern of SHG members, change in the cumulative saving pattern of SHGmembers per month, involvement in politics, achieving social harmony, achieving social justice, involvement in community action, sustainable quality and accountability, equity within SHGs,defaults and recoveries, and sustainability - financial value.

\section{Acknowledgement}

I deeply express my heartfelt gratitude to Editor or organisation of IOSR Journal for inspiring me to write this article.I came to know your refered journal through internet.I shall be highly grateful, thankful to you for making this article to publish it.I promise I fulfill all the formalities or ready pay accordingly if the article get selected. Please inform me through my email.

\section{References:}

[1]. ADB 2001 Legal empowerment: Advancing good governance and poverty reduction. Overview Report RETA 5856, Manila, Asian Development Bank.

[2]. Anonymous, 2005, Quick evaluation of beneficiary oriented (Sc/St) Programme of SGRY; Annual Report. Ministry of Rural Development, Government of India, KrishiBhavan, New Delhi.

[3]. Arunkumar, T.D., 2004, Profile of SHGs and their contribution for livestock development in Karnataka. M.Sc. (Agri.) Thesis, Univ. Agric. Sci., Dharwad.

[4]. Asthana S 1996. Women's health and women's empowerment locality perspective Health and Place, 2(1): 1-13.

[5]. B Debroy, AU Khan (Eds.): Integrating the Rural Poor into Markets New Delhi: Academic Foundation, pp.17-22.

[6]. Berry K 2003. Developing women: The traffic in ideas about women and their needs in Kangra India.

[7]. Campbell C, Jovchelovitch S 2000. Health, community and development: Towards a social psychology of participation Journal of Community and Applied Social Psychology, 10: 255-270.

[8]. Chakrabarti R 2004. The Indian microfinance experience-Accomplishments and challenges.

[9]. COSWAY Nancy 1997. Women and Water Supply a Partnership.23 ${ }^{\text {rd }}$ WEDC Conference on Water and Sanitation for all: Partnerships and Innovations Durban, South Africa, 1997.

[10]. Crawley H 1998. Living up to the empowerment claim? The potential of PRA. In: I Gujit, MK Shah (Eds.): The Myth of Community: Gender Issues in Participatory Development London: Intermediate Technology Publications, pp. 24-34.

[11]. DFID 2000. DFID, OIKOS and IIRR: Social and Institutional Issues in Watershed Management in India. International Institute of Rural Reconstruction July 2000.

[12]. Dube S C 1988. Modernization and Development - The Search for Alternative Paradigms London: Zed Books Ltd.

[13]. E.A Prameswara Gupta, Syed Rabmahulla and S.L.shankar "Impact of microfinance: A critical analysis "southern Economist, volume 48, No.18, January-15.2010,page No.29

[14]. Fernandez AP 1994. The MYRADA Experience People's Institutions for the Sustained and Equitable Management of Microwatershed MYRADA, Bangalore.

[15]. Fernandez AP 2003. People's Institutions Managing Natural Resource in the Context of a Watershed Strategy MYRADA, Bangalore.

[16]. Geeta Manmohan, Monika Tushir, Sumita chadha. (2008), ,Rural Banking and Micro finance” Southern Economist, Vol: 47, No.2.

[17]. Goetz AM 2001. Women Development Workers: Implementing Rural Credit Programs in Bangladesh New Delhi: Sage Publications.

[18]. Government of India 200 Tenth Five Year Plan 20022007.

[19]. Guijt I 1994. Water and Gender in Agenda 21. Report: Workshop on Gender and Water Resources Management, Stockholm,1-3 December 1993. Stockholm: IDA.

[20]. Gujit I, Shah M K 1998. Waking up to power, conflict and process In: I Gujit, Eds The Myth of Community: Gender Issues in Participatory Development. London intermediate Technology Publications, pp.1-23. 